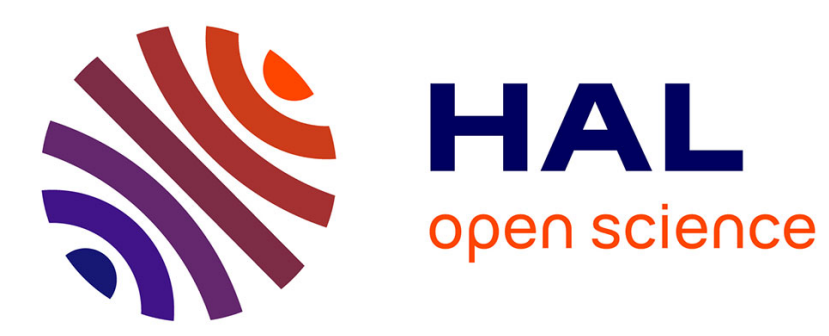

\title{
Competition between Humic Acid and Carbonates for Rare Earth Elements Complexation
}

\author{
Olivier Pourret, Mélanie Davranche, Gérard Gruau, Aline N. Dia
}

\section{To cite this version:}

Olivier Pourret, Mélanie Davranche, Gérard Gruau, Aline N. Dia. Competition between Humic Acid and Carbonates for Rare Earth Elements Complexation. Journal of Colloid and Interface Science, 2007, 305 (1), pp.25-31. 10.1016/j.jcis.2006.09.020 . insu-00154696

\section{HAL Id: insu-00154696 \\ https://hal-insu.archives-ouvertes.fr/insu-00154696}

Submitted on 14 Jun 2007

HAL is a multi-disciplinary open access archive for the deposit and dissemination of scientific research documents, whether they are published or not. The documents may come from teaching and research institutions in France or abroad, or from public or private research centers.
L'archive ouverte pluridisciplinaire HAL, est destinée au dépôt et à la diffusion de documents scientifiques de niveau recherche, publiés ou non, émanant des établissements d'enseignement et de recherche français ou étrangers, des laboratoires publics ou privés. 


\title{
Competition between Humic Acid and Carbonates for Rare Earth Elements Complexation
}

\author{
Olivier Pourret*, Mélanie Davranche, Gérard Gruau, Aline Dia
}

\author{
Géosciences Rennes - UMR CNRS 6118 \\ Université Rennes 1 - Campus de Beaulieu \\ 35042 Rennes Cedex, France
}

\footnotetext{
* Corresponding author: tel.: 332232360 42; fax: 332232360 90; e-mail address: olivier.pourret@univrennes1.fr.
} 
Abstract. The competitive binding of rare earth elements (REE) to humic acid (HA) and carbonates was studied experimentally at various $\mathrm{pH}$ and alkalinity values by combining Ultrafiltration and Inductively Coupled Plasma Mass Spectrometry techniques. The results show that the REE species occur as binary humate or carbonate complexes but not as ternary REEcarbonate-humate as previously proposed. The results also reveal the strong $\mathrm{pH}$ and alkalinity dependence of the competition as well as the existence of a systematic fractionation across the REE series. Specifically, carbonate complexation is at a maximum at $\mathrm{pH} 10$ and increase with increasing alkalinity and with the atomic number of the REE $\left(\mathrm{LuCO}_{3} \gg>\mathrm{LaCO}_{3}\right)$. Modelling of the data using Model VI and recently published stability constants for complexation of REE by humic acid well reproduced the experimental data, confirming the ability of Model VI to accurately determine REE speciation in natural waters. This modelling also confirms the reliability of recently published stability constants. This work shed more light not only on the competition between carbonates and HA for REE complexation but also on the reliability of WHAM 6 and Model VI for calculating the speciation of REE with organic matter in alkaline organic rich-water.

Key words: Rare earth elements, humic acid, carbonates, binding, speciation, ultrafiltration 


\section{Introduction}

The hydrochemical behavior of Rare Earth Elements (REE) is strongly influenced by their solution speciation $[1,2]$. Due to the complexation of REE by a large variety of ligands, only a small fraction of each REE occurs as free hydrated ions $\left(\mathrm{Ln}^{3+}-\mathrm{Ln}\right.$ as lanthanide) in circumneutral waters. In circumneutral waters, REE are mostly bound to humic substances (HM) such as fulvic acids (FA) and humic acids (HA) [3-5]. By contrast, in alkaline waters with high carbonates concentrations, REE complexation is generally dominated by carbonate complexes as $\mathrm{LnCO}_{3}{ }^{+}$and $\mathrm{Ln}\left(\mathrm{CO}_{3}\right)_{2}^{-}[2,5]$. However, competition reactions between carbonates and organic matter for REE complexation have not yet been experimentally constrained. At present, accurate models of REE chemistry in natural waters are only dependent on experimentally determined (i) REE carbonates complexation constants [6-12] and (ii) REE humic substances constants [13-15]. However, since there is no experimental data about the competition between carbonates and organic matter for REE complexation, an important piece of information is missing.

Previous studies [5, 16-18] based on speciation calculation of some REE (e.g., $\mathrm{La}^{3+}, \mathrm{Eu}^{3+}$, $\mathrm{Lu}^{3+}$ ) concluded that organic complexes dominate for intermediate $\mathrm{pH}$ range (from $\mathrm{pH} 4$ to 8 ) whereas carbonate complexes $\left(\mathrm{Ln}\left(\mathrm{CO}_{3}\right)_{2}{ }^{-}\right)$are the predominant species at alkaline $\mathrm{pH}(>8)$. However, as discussed by these authors themselves, speciation calculations may underestimate the LnHM complexes, especially at alkaline $\mathrm{pH}(>8)$. They suggest that this could have significant effects on ternary inorganic-colloid-HM-Ln interactions [17, 19, 20]. They also suggested that Ln speciation would be dominated by interactions with humic material. The lack of experimental data regarding LnHM interactions at neutral-to-alkaline $\mathrm{pH}$ leads to extrapolation and the speciation results obtained for alkaline waters should be regarded with caution [18]. Takahashi et al. [21] calculated speciation of $\mathrm{Ce}^{3+}, \mathrm{Eu}^{3+}$ and $\mathrm{Lu}^{3+}$ in solution in the presence of humic acid. Hydroxide carbonates and humate complexes were considered. Unlike the studies above, their results suggest that LnHA complexes should be predominant in a wide 
$\mathrm{pH}$ range (from $\mathrm{pH} 3$ to 10.5 ), and even more at higher $\mathrm{HA}$ concentrations. $\mathrm{Ln}\left(\mathrm{CO}_{3}\right)_{2}^{-}$should be dominant at $\mathrm{pH}$ higher than 10.5. These observations are further illustrated by a new study considering Model VI fitted complexation constants between REE and HA. Model VI calculated high proportions of light REE (LREE) complexed with organic matter under alkaline $\mathrm{pH}$ conditions [15]. Comparison of REE speciation model calculations, taking into account organic ligands, shows strong differences between each model regarding the competition between humic substances and carbonates for REE complexation.

In order to assess humic acid and carbonates competition for REE at alkaline $\mathrm{pH}$, batch equilibration experiments with REE, Aldrich HA and carbonates were performed simultaneously for the 14 naturally occurring REE. This new dataset was obtained using an experimental method which combines an ultrafiltration technique and Inductively Coupled Plasma Mass Spectrometry. These experiments were designed to elucidate the $\mathrm{pH}$ range where REE-humate complexes would be dominant in natural organic-rich waters for various alkalinity concentrations and test whether significant formation of ternary complexes can take place in such conditions. Moreover, Humic Ion Binding Model VI included in WHAM 6 - a model that does not considered ternary surface complexes - was used to model the binding of lanthanides to humic substances [22]. This study should also evidence the ability of the newly determined HA-REE binding constants [15] to accurately predict the speciation of REE in alkaline waters.

\section{Materials and Methods}

\subsection{Experimental Binding of Rare Earth Elements by Humic Acid and Carbonates}

All chemicals used were of analytical grade, and all the experimental solutions were prepared with doubly deionized water (MilliQ system, Millipore ${ }^{\mathrm{TM}}$ ). Complexes were prepared in polyethylene containers previously soaked in $10 \%$ Ultrapure $\mathrm{HNO}_{3}$ for $48 \mathrm{~h}$ at $60{ }^{\circ} \mathrm{C}$, then rinsed 
with MilliQ water for $24 \mathrm{~h}$ at $60{ }^{\circ} \mathrm{C}$ to remove all possible REE contamination sources. Synthetic REE solutions were prepared from nitrate REE standards (10 ppm, Accu Trace ${ }^{\mathrm{TM}}$ Reference Standard). All experiments were carried out at room temperature, i.e. $20{ }^{\circ} \mathrm{C} \pm 2$.

\subsubsection{Humic acid}

Purified humate, referred to below as HA (humic acid), was obtained from Aldrich ${ }^{\mathrm{TM}}$ humic acid (Aldrich $\left.{ }^{\mathrm{TM}}, \mathrm{H1}, 675-2\right)$ following the protocol described by Vermeer et al. [23]. HA sample was freeze-dried and stored in a glass container at room temperature. HA obtained was ash free and in its protonated form, with the following elemental composition (in weight percent): $\mathrm{C}=55.8 \%, \mathrm{O}=38.9 \%, \mathrm{H}=4.6 \%, \mathrm{~N}=0.6 \%$. REE concentrations in HA were below the detection limit of ICP-MS method (i.e. below $1 \mathrm{ppt}$ ). HA has a mean molecular weight of 23 $\mathrm{kDa}$ [23]. Prior to use, the freeze-dried humate was resuspended overnight in an $0.001 \mathrm{~mol} \mathrm{~L}^{-1}$ $\mathrm{NaCl}$ electrolyte solution at $\mathrm{pH}=10$, to ensure complete dissolution of the sample $[24,25]$.

\subsubsection{Experimental set-up}

REE complexation with HA and carbonates was investigated using a standard batch equilibration technique. $100 \mathrm{~mL}$ of solutions were prepared with $50 \mathrm{ppb}$ of each REE (e.g., 360 nmol L ${ }^{-1} \mathrm{La}$ to $286 \mathrm{nmol} \mathrm{L}{ }^{-1} \mathrm{Lu}$ ), $5 \mathrm{mg} \mathrm{L}^{-1}$ of $\mathrm{HA}$ and various concentration of $\mathrm{NaHCO}_{3}$ (from $10^{-3}$ to $10^{-2} \mathrm{~mol} \mathrm{~L}^{-1}$ ) in a $10^{-3} \mathrm{~mol} \mathrm{~L}^{-1} \mathrm{NaCl}$-solution. Prior to addition of $\mathrm{NaHCO}_{3}$, the $\mathrm{pH}$ of the solution was approximately 4 . The initial hydroxide concentration was negligible and concentration of $\mathrm{LnOH}^{2+}$ was therefore minimal. After addition of $\mathrm{NaHCO}_{3}$, $\mathrm{pH}$ was adjusted to the tested $\mathrm{pH}$ range, from 6 to 11 by adding $\mathrm{NaOH}\left(4 \mathrm{~mol} \mathrm{~L}^{-1}\right)$. The $\mathrm{pH}$ was measured with a combined Radiometer Red Rod electrode. The electrode was calibrated with $\mathrm{WTW}^{\mathrm{TM}}$ standard solutions ( $\mathrm{pH} \mathrm{4,7}$ and 10). The accuracy of the $\mathrm{pH}$ measurement was \pm 
$0.05 \mathrm{pH}$ unit. Experimental solutions were stirred for $48 \mathrm{~h}$ (the equilibrium time was determined from preliminary kinetic experiments) to allow equilibration and partitioning of REE between the aqueous solution and the humate suspension. Aliquots of $10 \mathrm{~mL}$ were sampled twice: at the beginning of the experiment; and after $48 \mathrm{~h}$ at equilibrium state. REE complexed by the HA were separated from the remaining inorganic REE by ultrafiltration. Ultrafiltrations were carried out by centrifugating the $10 \mathrm{~mL}$ solution samples through $15 \mathrm{~mL}$ centrifugal tubes equipped with permeable membranes of $5 \mathrm{kDa}$ pore size (Millipore Amicon Ultra-15). All centrifugal filter devices used were washed and rinsed with $0.1 \mathrm{~mol} \mathrm{~L}^{-1} \mathrm{HCl}$ and MilliQ water two times before use in order to minimize contamination. Centrifugations were performed using a Jouan G4.12 centrifuge with swinging bucket rotor at $3000 \mathrm{~g}$ for 30 minutes. This allowed the REE-HA complexes to be quantitatively separated from inorganic REE species. The selectivity of the $5 \mathrm{kDa}$ membrane regards to the REE-HA complexes was verified by monitoring the Dissolved Organic Carbon (DOC) contents of the ultrafiltrates. Results show that the latter were systematically lower or equal to blank values (below $0.1 \mathrm{ppm}$ ). Possible adsorption of inorganic REE species onto the membrane or onto cell walls was also monitored. Inorganic REE solutions of given REE concentration were ultrafiltrated several times. Results showed that between 98.91 (for $\mathrm{Ho}$ ) and $99.98 \%$ (for $\mathrm{Yb}$ ) of the REE present in solution were recovered in the ultrafiltrates, demonstrating that none REE were adsorbed either on the membranes or on the walls of the cell devices.

Amount of REE complexed with HA correspond to the difference between the initial REE concentration and the remaining $\mathrm{REE}$ concentration into the $<5 \mathrm{kDa}$ ultrafiltrates. REE concentrations were determined by using an Agilent Technologies ${ }^{\mathrm{TM}}$ HP4500 ICP-MS instrument. Quantitative analyses were performed using a conventional external calibration procedure. Three external standard solutions with REE concentrations similar to the analyzed samples were prepared from a multi-REE standard solution (Accu Trace ${ }^{\mathrm{TM}}$ Reference, $10 \mathrm{mg} \mathrm{L}^{-1}$, USA). Indium was added to all samples as an internal standard at a concentration of $0.87 \mu \mathrm{mol} \mathrm{L}^{-1}(100 \mathrm{ppb})$ to 
correct for instrumental drift and possible matrix effects. Indium was also added to the external standard solutions. Calibration curves were calculated from measured REE/indium intensity ratios. The instrumental error on REE analysis in our laboratory as established from repeated analyses of multi-REE standard solution (Accu Trace ${ }^{\mathrm{TM}}$ Reference, USA) and of the SLRS-4 water standard is below $\pm 2 \%[4,25]$. Chemical blanks of individual REE were all lower than detection limit (1 ppt), which is negligible since they are three to four orders of magnitude lower than the concentrations measured in the synthetic solutions used for the complexation experiments. DOC concentrations were determined using a Shimadzu 5000 TOC analyzer. The accuracy of DOC concentration measurements is estimated at $\pm 5 \%$ as determined by repeated analyses of freshly prepared standard solutions (potassium biphtalate). Carbonates concentrations

were determined by potentiometric titrations $\left(\mathrm{HCl} 0.1 \mathrm{~mol} \mathrm{~L}^{-1}\right)$, with $\mathrm{Gran}$ method analysis. The uncertainty is better than $5 \%$.

In order to check that no retention of REE or carbonates occurs inside the membrane during ultrafiltration, mass balance calculations were performed. The initial concentration of each element is compared with the sum of each element concentration in the ultrafiltrate and in the retentate. In the presented experiments, mass balanced calculations show that $>98 \%$ of the REE and $>95 \%$ of the carbonates and DOC were recovered. Moreover, in order to verify that no precipitation occurs, samples were filtrated at $0.2 \mu \mathrm{m}$ before ultrafiltration. Concentrations of REE, HA and carbonates were systematically identical within analytical uncertainties in the 0.2 $\mu \mathrm{m}$ filtrates and the raw samples.

\subsection{WHAM 6 and Humic Ion Binding Model VI}

WHAM 6 (version 6.0.10), incorporating Humic Ion Binding Model VI (Model VI), was used to calculate REE speciation in the batch experiments. Model VI has been described in detail by Tipping [22]. The model is a discrete binding site model in which binding is modified by 
electrostatic interactions. There is an empirical relation between the net humic charge and an electrostatic interaction factor. The discrete binding sites are represented by two types of sites (types A and B), and within each type of site there are four different sites present in equal amounts. The two types of sites are described by intrinsic proton binding constants $\left(\mathrm{pK}_{\mathrm{A}}\right.$ and $\left.\mathrm{pK}_{\mathrm{B}}\right)$ and spreads of the values $\left(\Delta \mathrm{pK}_{\mathrm{A}}\right.$ and $\left.\Delta \mathrm{pK} \mathrm{K}_{\mathrm{B}}\right)$ within each type of sites. There are $\mathrm{n}_{\mathrm{A}}\left(\mathrm{mol} \mathrm{g}^{-}\right.$

$\left.{ }^{1}\right)$ A-type sites (associated with carboxylic type groups) and $n_{B}=n_{A} / 2\left(\mathrm{~mol} \mathrm{~g}^{-1}\right)$ B-type of sites (often associated with phenolic type groups). Metal binding occurs at single proton binding sites or by bidentate complexation between pairs of sites depending on a proximity factor that defines whether pairs of proton binding groups are close enough to form bidentate sites. Type A and Type $B$ sites have separate intrinsic binding constants ( $\log \mathrm{K}_{\mathrm{MA}}$ and $\left.\log \mathrm{K}_{\mathrm{MB}}\right)$, together associated with a parameter, $\Delta \mathrm{LK}_{1}$, defining the spreads of values around the medians. A further parameter, $\Delta \mathrm{LK}_{2}$, takes into account a small number of stronger sites. By considering results from many datasets, a universal average value of $\Delta \mathrm{LK}_{1}$ is obtained, and a correlation established between $\log$ $\mathrm{K}_{\mathrm{MB}}$ and $\log \mathrm{K}_{\mathrm{MA}}$ [22]. Then, a single adjustable parameter $\left(\log \mathrm{K}_{\mathrm{MA}}\right)$ is necessary to fully describe metal binding. Generic parameters for HA are presented in Table 1. WHAM 6 databases were modified and included new log $\mathrm{K}_{\mathrm{MA}}$ for REE complexation with humic acid [15] and wellaccepted, infinite dilution $\left(25^{\circ} \mathrm{C}\right)$ stability constants for REE carbonates complexes [11].

\section{Experimental Results}

Experimental data are reported for three REE ( $\mathrm{La}, \mathrm{Eu}$ and $\mathrm{Lu}$ ) in Table 2 and illustrated in Fig. 1. Competition between HA and carbonates for REE complexation is examined by considering the mass fraction inorganic REE species as a function of $\mathrm{pH}$. The complementary fraction is made up of REE organic complexes. Based on speciation calculations of the inorganic fraction using WHAM 6, REE were shown to consist mostly of carbonate complexes. In these experimental conditions (see section 2.1), hydroxide and free species are only present at very low 
concentrations (as regards to speciation calculations $<0.2 \%$ and $<3.8 \%$ of the inorganic fraction for La, respectively). Two REE-carbonate complexation reactions are considered in Fig. 1 and described by the following equations:

$$
\begin{aligned}
& \mathrm{Ln}^{3+}+\mathrm{CO}_{3}{ }^{2-} \leftrightharpoons \mathrm{LnCO}_{3}{ }^{+} \\
& \mathrm{Ln}^{3+}+2 \mathrm{CO}_{3}{ }^{2-} \leftrightharpoons \mathrm{Ln}\left(\mathrm{CO}_{3}\right)_{2}^{-}
\end{aligned}
$$

whereas humic complexation are described by the following equation:

$$
\mathrm{Ln}^{3+}+\mathrm{HA}^{-} \leftrightharpoons \mathrm{LnHA}^{2+}
$$

As shown in Figure 1, $\mathrm{LnCO}_{3}{ }^{+}$and $\mathrm{Ln}\left(\mathrm{CO}_{3}\right)_{2}{ }^{-}$concentrations depend strongly on the $\mathrm{pH}-$ and the carbonate content. $\mathrm{LnCO}_{3}{ }^{+}$concentrations decrease with $\mathrm{pH}$ increase whereas $\mathrm{Ln}\left(\mathrm{CO}_{3}\right)_{2}{ }^{-}$ concentrations increase while $\mathrm{pH}$ increases. Moreover, $\mathrm{Ln}\left(\mathrm{CO}_{3}\right)_{2}{ }^{-}$and $\mathrm{LnCO}_{3}{ }^{+}$concentrations increase with the solution alkalinity. The slight "bump" in the $\mathrm{pH}$ range 8-8.5 corresponds to the competitive reaction between mono- (Eq. [1]) and di- (Eq. [2]) carbonato-complexation reactions. This "bump" is more significant for LREE than for heavy REE (HREE), a result consistent with the difference in complexation constants of LREE- and HREE-carbonate complexes [11]. Thus, a fractionation is apparent between LREE and HREE regarding their complexation to carbonate. Let's consider for example a $\mathrm{pH} 10$ value of alkalinity $10^{-2} \mathrm{~mol} \mathrm{~L}^{-1}$ and the results observed under these conditions. Only $15 \%$ of La is bound to carbonate whereas $30 \%$ of Eu and up to $60 \%$ of Lu are bound to carbonate. Moreover, carbonate concentrations were systematically identical in the ultrafiltrates and in the initial batches (within the uncertainty of the measures). Calculation considering that 1:1:2 ternary complexes could be formed were performed and further demonstrate that no carbonate was bound to HA in our experiments (Ln concentrations are several order of magnitude higher than maximum $\mathrm{CO}_{3}{ }^{2-}$ concentration variation between ultrafiltrates and initial batches). Consequently, no additional interactions 
between metal $\left(\mathrm{Ln}^{3+}\right)$, ligand $\left(\mathrm{CO}_{3}{ }^{2-}\right)$ and surface (HA) occurred demonstrating that ternary surface complexes did not develop.

\section{Discussion}

4.1. Lack of evidence of ternary complexe formation

A common question when dealing with metal (M) speciation in systems containing humic substances (HS) such as HA and inorganic ligands (L) such as carbonate is, whether or not, ternary complexe (M-HA- $\mathrm{L}_{m}$ with m corresponding to the ligand stoechiometry), can form.

Information about ternary complex formation in the literature is scarce, especially concerning REE. Even if such a mechanism was suggested for REE (e.g., [17]), only a few experimental studies brought direct evidence for possible formation of such complexes $[19,20]$. Dierckx et al. [19] provided evidence for mixed-ligand complex formation of $\mathrm{Eu}^{3+}$ with humic acid and inorganic ligands (i.e., $\mathrm{CO}_{3}{ }^{2-}$ ). However, the interpretation of Dierckx et al. [19] left some open questions, as they observed formation of either M-HA or M-HA- $\mathrm{L}_{2}$ complexes formed across the whole range of L concentrations, without observing the formation of M-HA- $\mathrm{L}_{1}$ complexes. These observations are unusual with respect to common experiences found with inorganic ligands and oxide-based surfaces (e.g., [26]). Moreover, Glaus et al. [27, 28] have shown that the formation of mixed-ligand-humic complexes is rather weak as compared to the formation of simple ligand-complexes with inorganic ligands. Ternary-humic complexes appear thus less important than predicted by the data of Dierckx et al. [19].

A possible explanation for the absence of ternary complex formation in the present work might be the electrostatic repulsion between the negatively charged $\mathrm{HA}$ and $\mathrm{Ln}-\mathrm{CO}_{3}$. Due to the polyelectrolyte character of HA, this repulsion is stronger than that occurring between lowmolecular weights ligands. Schindler [26] reported that ternary complexes with $\mathrm{SiO}_{2}$ and $\mathrm{TiO}_{2}$ 
surfaces are rather weak. Both surfaces are negatively charged at the $\mathrm{pH}$ of Schindler's experiments and can therefore be considered as analogues to HS. Ternary surface complexes are thus not as important as previously stated and do not need to be considered in REE speciation calculation in systems dominated by organic and alkaline water.

\subsection{Competition between humic acid and carbonates for REE complexation}

In order to further constrain the competition between humic acid and carbonates for REE complexation, calculation using Model VI in WHAM 6 were performed. Calculations were conducted using Model VI in which a new determined log $\mathrm{K}_{\mathrm{MA}}$ dataset for HA-REE complexation was integrated [15]. These $\log \mathrm{K}_{\mathrm{MA}}$ values were estimated from REE complexation by HA experiments without any competing effect. The log $\mathrm{K}_{\mathrm{MA}}$ values range from $2.58 \pm 0.16$ (for $\mathrm{La}$ ) to $2.65 \pm 0.15$ (for $\mathrm{Eu}$ ); these latter being slightly higher than the one estimated by Lead et al. [18] (2.36 \pm 0.13$)$. These calculations only considered trivalent REE species. Speciation calculations are illustrated on Figs. 1.2a, b and c for La, Eu and Lu, respectively, for the three experimental conditions (i.e. increasing alkalinity and $\mathrm{pH}$ ). In particular, Model VI reproduced quite well the observed dependence of the proportion of carbonate complexes with $\mathrm{pH}$ and alkalinity. However, the observed experimental "bump" is not modelled by Model VI. This is due

to the fact that only $\mathrm{Ln}$ complexation with two $\mathrm{CO}_{3}{ }^{2-}$ is predicted whereas $\mathrm{Ln}$ complexation with a single $\mathrm{CO}_{3}{ }^{2-}$ is overwhelmed by competition with HA (Fig. 1.2). Comparison between experimental and calculated values evidences that Model VI slightly underpredicts (0 to $11 \%$ ) REE complexation by carbonate (Figs. 1.2a, b and c). Root mean square error (rmse) values represent the sum of the squares of the difference between observed and calculated values. As indicated by the rmse systematically below 0.06 (Fig. 1.2), fits can be considered of good quality, even if rmse values increase when competition between HA and carbonates is more developed 
(i.e., for alkalinity of $10^{-2} \mathrm{~mol} \mathrm{~L}^{-1}$ ). Overall, it is clear that LREE to Middle REE (MREE) are strongly bound to HA whereas HREE are more shared between HA and carbonate fractions.

More in detail, $\mathrm{pH}$ is a crucial parameter affecting binding, since it regulates competition between HA and carbonates. Carbonate complexation mostly affects REE speciation in alkaline waters ( $\mathrm{pH}$ above 8.5). These observations validate both the use of Model VI [22] and of the $\log \mathrm{K}_{\mathrm{MA}}$ (REE-HA) dataset determined by Pourret et al. [15] to confidently predict REE speciation in natural alkaline waters. As stated by Tipping [22], an important issue in increasing WHAM and Model VI capacity to perform chemical speciation calculations for field situations is whether significant formation of ternary complexes takes place. Simulations on some trace metals may have indeed significantly underestimated the extent of metal binding as compared to observation especially when binding occurs through the formation of ternary complexes [29]. As evidenced by experimental results, none ternary surface complexation occurs between REE, HA and carbonate. WHAM 6 is thus applicable to calculate REE speciation in natural water even if it does not take into account ternary surface complexation. This study combined with a previous one [30] now covers a wide range of natural conditions and shows that WHAM and Model VI are reliable in calculating the speciation of REE with organic matter in acidic and circumneutral DOC-rich ground- and river waters [30] and in alkaline organic rich-water (this study). These results suggest that dissolved organic complexes of the REE are more important than carbonates complexes for LREE to MREE and as important for HREE in World Rivers. As previously suggested by Tang and Johannesson [5], the role played by organic material to complex REE increases our understanding of REE cycling in the hydrosphere. This also questions the fact that carbonate complexes could dominate the REE cycle in circumneutral pH-low carbonate concentrations fresh waters.

\section{Conclusions}


Experimental studies of HA and carbonate competition for REE complexation were carried out for the 14 naturally REE simultaneously. Experimental method combines an ultrafiltration technique and ICP-MS to determine REE concentrations in the different pools. Competition between HA and carbonates for REE complexation is $\mathrm{pH}$ - and carbonate concentrationdependent. There is no evidence of any ternary surface complex as previously proposed (e.g., [19]). These experiments elucidate the $\mathrm{pH}$ range where humate complexes could be the dominant species of REE(III) in natural organic-rich waters, for various alkalinity concentrations. Carbonates are the only REE predominant species for HREE at higher alkalinity concentrations, above $\mathrm{pH}$ 8.5. A fractionation develops between LREE and HREE relative to REE complexation to carbonates, especially at higher alkalinity. Modelling calculations were performed with Model VI [22]. Calculations were consistent with experimental result, namely the $\mathrm{pH}$ - and carbonate concentration-dependence. The results show the influence of the competitive reactions between carbonates and HA for REE complexation at alkaline pH. All these observations allow validating the $\log \mathrm{K}_{\mathrm{MA}}$ (REE-HA) dataset [15] that can be, therefore, used with confidence to predict REE speciation in natural alkaline waters. They also evidence the reliability of WHAM 6 and Model VI in calculating the speciation of REE with organic matter in alkaline organic richwater, as ternary surface complexes do not need to be modelled. Overall, the results of this study suggest that further considerations about organic matter should be taken into account especially at alkaline $\mathrm{pH}$ in organic-rich waters. 


\section{Acknowledgements}

We thank the technical staff at Rennes (M. Le Coz-Bouhnik, O. Hénin and P. Petitjean) for their assistance during the experimental and analytical work. Dr. R. E. Martinez is acknowledged for useful discussions and English corrections. This research was supported by the CPER programs "Développement de la Recherche sur la Maîtrise de la Qualité de l'Eau en Bretagne" jointly funded by the French Government and the Council of Rennes Métropole. We thank two anonymous reviewers for their constructive comments. 


\section{References}

[1] S.A. Wood, The aqueous geochemistry of the rare-earth elements and yttrium. 1. Review of the available low-temperature data for inorganic complexes and inorganic REE speciation in natural waters, Chem. Geol. 82 (1990) 159-186.

[2] R.H. Byrne and E.R. Sholkovitz, Marine chemistry and geochemistry of the lanthanides, in: Handbook on the Physics and Chemistry of Rare Earths, K.A. Gschneidner Jr. and L.R. Eyring, eds. 23, pp. 497-593, Elsevier Sciences B.V., 1996.

[3] J. Viers, B. Dupré, M. Polvé, J. Schott, J.-L. Dandurand and J.J. Braun, Chemical weathering in the drainage basin of a tropical watershed (Nsimi-Zoetele site, Cameroon): comparison between organic-poor and organic-rich waters, Chem. Geol. 140 (1997) 181206.

[4] A. Dia, G. Gruau, G. Olivié-Lauquet, C. Riou, J. Molénat and P. Curmi, The distribution of rare earth elements in groundwaters: assessing the role of source-rock composition, redox changes and colloidal particle, Geochim. Cosmochim. Acta 64 (2000) 4131-4151.

[5] J. Tang and K.H. Johannesson, Speciation of rare earth elements in natural terrestrial waters: Assessing the role of dissolved organic matter from the modeling approach, Geochim. Cosmochim. Acta 67 (2003) 2321-2339.

[6] K.J. Cantrell and R.H. Byrne, Rare earth element complexation by carbonate and oxalate ions, Geochim. Cosmochim. Acta 51 (1987) 597-605.

[7] F.J. Millero, Stability constants for the formation of rare earth inorganic complexes as a function of ionic strength, Geochim. Cosmochim. Acta 56 (1992) 3123-3132.

[8] J.H. Lee and R.H. Byrne, Examination of comparative rare earth element complexation behavior using linear free-energy relationships, Geochim. Cosmochim. Acta 56 (1992) $1127-1137$.

[9] Y.-G. Liu, M.R.U. Miah and R.A. Schmitt, Cerium: A chemical tracer for paleo-oceanic redox conditions, Geochim. Cosmochim. Acta 52 (1988) 1361-1371. 
[10] A. Ohta and I. Kawabe, Rare earth element partitioning between Fe oxyhydroxide precipitates ans aqueous $\mathrm{NaCl}$ solutions doped with $\mathrm{NaHCO}$ : Determinations of rare earth element complexation constants with carbonate ions, Geochem. J. 34 (2000) 439454.

[11] Y.-R. Luo and R.H. Byrne, Carbonate complexation of yttrium and the rare earth elements in natural rivers, Geochim. Cosmochim. Acta 68 (2004) 691-699.

[12] K.A. Quinn, R.H. Byrne and J. Schijf, Comparative scavenging of yttrium and the rare earth elements in seawater: competitive influences of solution and surface chemistry, Aquat. Geochem. 10 (2004) 59-80.

[13] Y. Yamamoto, Y. Takahashi and H. Shimizu, Systematics of stability constants of fulvate complexes with rare earth ions, Chem. Lett. 34 (2005) 880-881.

[14] J.E. Sonke and V.J.M. Salters, Lanthanide-humic substances complexation. I. Experimental evidence for a lanthanide contraction effect, Geochim. Cosmochim. Acta 70 (2006) 1495-1506.

[15] O. Pourret, M. Davranche, G. Gruau and A. Dia, Rare Earth Elements complexation with humic acid, Chem. Geol. In review (2006).

[16] S.A. Wood, The aqueous geochemistry of the rare-earth elements: Critical stability constants for complexes with simple carboxylic acids at $25^{\circ} \mathrm{C}$ and 1 bar and their application to nuclear waste management, Eng. Geol. 34 (1993) 229-259.

[17] A.J. Fairhurst, P. Warwick and S. Richardson, The influence of humic acid on the adsorption of europium onto inorganic colloids as a function of $\mathrm{pH}$, Colloids Surf. A 99 (1995) 187-199.

[18] J.R. Lead, J. Hamilton-Taylor, A. Peters, S. Reiner and E. Tipping, Europium binding by fulvic acids, Anal. Chim. Acta 369 (1998) 171-180.

[19] A. Dierckx, A. Maes and J. Vancluysen, Mixed complex formation of Eu3+ with humic acid and a competing ligand, Radiochim. Acta 66/67 (1994) 149-156. 
[20] C. Moulin, J. Wei, P. Van Iseghem, I. Laszak, G. Plancque and V. Moulin, Europium complexes investigations in natural waters by time-resolved laser-induced fluorescence, Anal. Chim. Acta 396 (1999) 253-261.

[21] Y. Takahashi, Y. Minai, S. Ambe, Y. Makide and F. Ambe, Comparison of adsorption behavior of multiple inorganic ions on kaolinite and silica in the presence of humic acid using the multitracer technique, Geochim. Cosmochim. Acta 63 (1999) 815-836.

[22] E. Tipping, Humic Ion-Binding Model VI: an improved description of the interactions of protons and metal ions with humic substances, Aquat. Geochem. 4 (1998) 3-48.

[23] A.W.P. Vermeer, W.H. Van Riemsdijk and L.K. Koopal, Adsorption of humic acid to mineral particles. 1. Specific and electrostatic interactions, Langmuir 14 (1998) 28102819.

[24] M. Davranche, O. Pourret, G. Gruau and A. Dia, Impact of humate complexation on the adsorption of REE onto Fe oxyhydroxide, J. Colloid Interface Sci. 277 (2004) 271-279.

[25] M. Davranche, O. Pourret, G. Gruau, A. Dia and M. Le Coz-Bouhnik, Adsorption of REE(III)-humate complexes onto MnO2: Experimental evidence for cerium anomaly and lanthanide tetrad effect suppression, Geochim. Cosmochim. Acta 69 (2005) 4825-4835.

[26] P.W. Schindler, Co-adsorption of metal ions and organic ligands: formation of ternary surface complexes, in: Mineral-Water Interface Geochemistry, M.F. Hochella and A.F. White, eds. 23, pp. 281-307, Mineralogical Society of America, 1990.

[27] M.A. Glaus, W. Hummel and L.R. Van Loon, Stability of mixed-ligand complexes of metal ions with humic substances and low molecular weight ligands, Environ. Sci. Technol. 29 (1995) 2150-2153.

[28] M.A. Glaus, W. Hummel and L.R. Van Loon, Trace metal-humate interactions. I. Experimental determination of conditional stability constants, Appl. Geochem. 15 (2000) 953-973. 
[29] S. Lofts and E. Tipping, Modelling the solid-solution partitioning of metals in environmental systems, Environmental Geochemistry and Health 21 (1999) 299-304.

[30] O. Pourret, M. Davranche, G. Gruau and A. Dia, Organic complexation of rare earth elements in natural waters: Evaluating model calculations from ultrafiltration data, Geochim. Cosmochim. Acta Revised version in review (2006).

\section{Tables and Figures Captions}

Table 1. Model VI parameters for humic acid [22].

Table 2. Proportion of Ln species in the ultrafiltrate.

Fig. 1. Proportion of inorganic species for (a) La, (b) Eu and (c) Lu (experimental concentrations:

$50 \mathrm{ppb}$ of each REE, $5 \mathrm{mg} \mathrm{L} \mathrm{L}^{-1}$ of $\mathrm{HA}$ and alkalinity of $10^{-2} \mathrm{~mol} \mathrm{~L}^{-1}$ ). Squares represent experimental data points (proportion of species in the ultrafiltrate), whereas solid lines represent modelled total inorganic species, dash lines modelled $\mathrm{LnCO}_{3}{ }^{+}$and dot lines modelled $\mathrm{Ln}\left(\mathrm{CO}_{3}\right)_{2}{ }^{-}$ (see text for details).

Fig. 2. Comparison between Model VI calculations and experiments. Proportion of lanthanides bound to carbonates as a function of $\mathrm{pH}$ for various alkalinities: (a) $\mathrm{La}$, (b) Eu and (c) Lu. 


\begin{tabular}{lll}
\hline Parameter & Description & Values \\
\hline $\mathrm{n}_{\mathrm{A}}$ & Amount of type A sites $\left(\mathrm{mol} \mathrm{g}^{-1}\right)$ & $3.310^{-3}$ \\
$\mathrm{n}_{\mathrm{B}}$ & Amount of type B sites $\left(\mathrm{mol} \mathrm{g}^{-1}\right)$ & $0.5 \mathrm{x}_{\mathrm{A}}$ \\
$\mathrm{pK}_{\mathrm{A}}$ & Intrinsic proton dissociation constant for type A sites & 4.1 \\
$\mathrm{pK}_{\mathrm{B}}$ & Intrinsic proton dissociation constant for type B sites & 8.8 \\
$\Delta \mathrm{pK}_{\mathrm{A}}$ & Distribution terms that modifies $\mathrm{pK}_{\mathrm{A}}$ & 2.1 \\
$\Delta \mathrm{pK}_{\mathrm{B}}$ & Distribution terms that modifies $\mathrm{pK}_{\mathrm{B}}$ & 3.6 \\
$\log \mathrm{K}_{\mathrm{MA}}$ & Intrinsic equilibrium constant for metal binding at type A sites & From experimental data [15] \\
$\log \mathrm{K}_{\mathrm{MB}}$ & Intrinsic equilibrium constant for metal binding at type B sites & $3.39 \log \mathrm{K}_{\mathrm{MA}}-1.15$ \\
$\Delta \mathrm{LK}_{1}$ & Distribution term that modifies log $\mathrm{K}_{\mathrm{MA}}$ & $2.8(\mathrm{REE})$ \\
$\Delta \mathrm{LK}_{2}$ & Distribution term that modifies the strengths of bidentate and tridentate sites & $0.55 \log \mathrm{K}_{\mathrm{NH} 3}=0.29$ (REE) \\
$\mathrm{P}$ & Electrostatic parameter & -330 \\
$\mathrm{~K}_{\text {sel }}$ & Selectivity coefficient for counterion accumulation & 1 \\
$\mathrm{M}$ & Molecular weight & $15000 \mathrm{Da}$ \\
$\mathrm{r}$ & Molecular radius & $1.72 \mathrm{~nm}$ \\
\hline
\end{tabular}

Table 1. 


\begin{tabular}{cccccccccccc}
\hline & \multicolumn{3}{c}{ Alkalinity: $10^{-3} \mathrm{~mol} \mathrm{~L}^{-1}$} & \multicolumn{4}{c}{ Alkalinity: 5} & $10^{-3} \mathrm{~mol} \mathrm{~L}^{-1}$ & \multicolumn{3}{c}{ Alkalinity: $10^{-2} \mathrm{~mol} \mathrm{~L}^{-1}$} \\
$\mathrm{pH}$ & $\mathrm{La}$ & $\mathrm{Eu}$ & $\mathrm{Lu}$ & $\mathrm{pH}$ & $\mathrm{La}$ & $\mathrm{Eu}$ & $\mathrm{Lu}$ & $\mathrm{pH}$ & $\mathrm{La}$ & $\mathrm{Eu}$ & $\mathrm{Lu}$ \\
\hline 6.64 & 0.36 & 0.44 & 0.67 & 6.81 & 2.83 & 3.55 & 6.02 & 7 & 3.55 & 6.81 & 21.76 \\
7.02 & 0.37 & 0.5 & 0.68 & 7.37 & 3.92 & 5.28 & 10.95 & 7.48 & 7.25 & 11.7 & 30.89 \\
7.09 & 0.53 & 0.64 & 0.85 & 8.05 & 5.71 & 8.17 & 14.8 & 8.11 & 6.29 & 11.93 & 31.63 \\
7.45 & 0.43 & 0.51 & 0.7 & 8.6 & 3.68 & 6.95 & 18.42 & 8.71 & 5.61 & 15.73 & 42.77 \\
8.26 & 0.5 & 0.57 & 0.71 & 9.1 & 5.41 & 10.58 & 26.16 & 9.03 & 8.39 & 21.35 & 50.42 \\
9.03 & 0.43 & 0.47 & 0.55 & 9.58 & 10.86 & 18.04 & 33.13 & 9.53 & 11.37 & 27.21 & 57.76 \\
9.84 & 0.29 & 0.25 & 0.25 & 10.04 & 5.46 & 13.43 & 31.58 & 10.04 & 13.56 & 30.77 & 59.5 \\
10.49 & 0.55 & 0.62 & 0.77 & 10.57 & 5.08 & 6.86 & 10.81 & 10.5 & 12.01 & 23.98 & 51.16 \\
\hline
\end{tabular}

Table 2. 

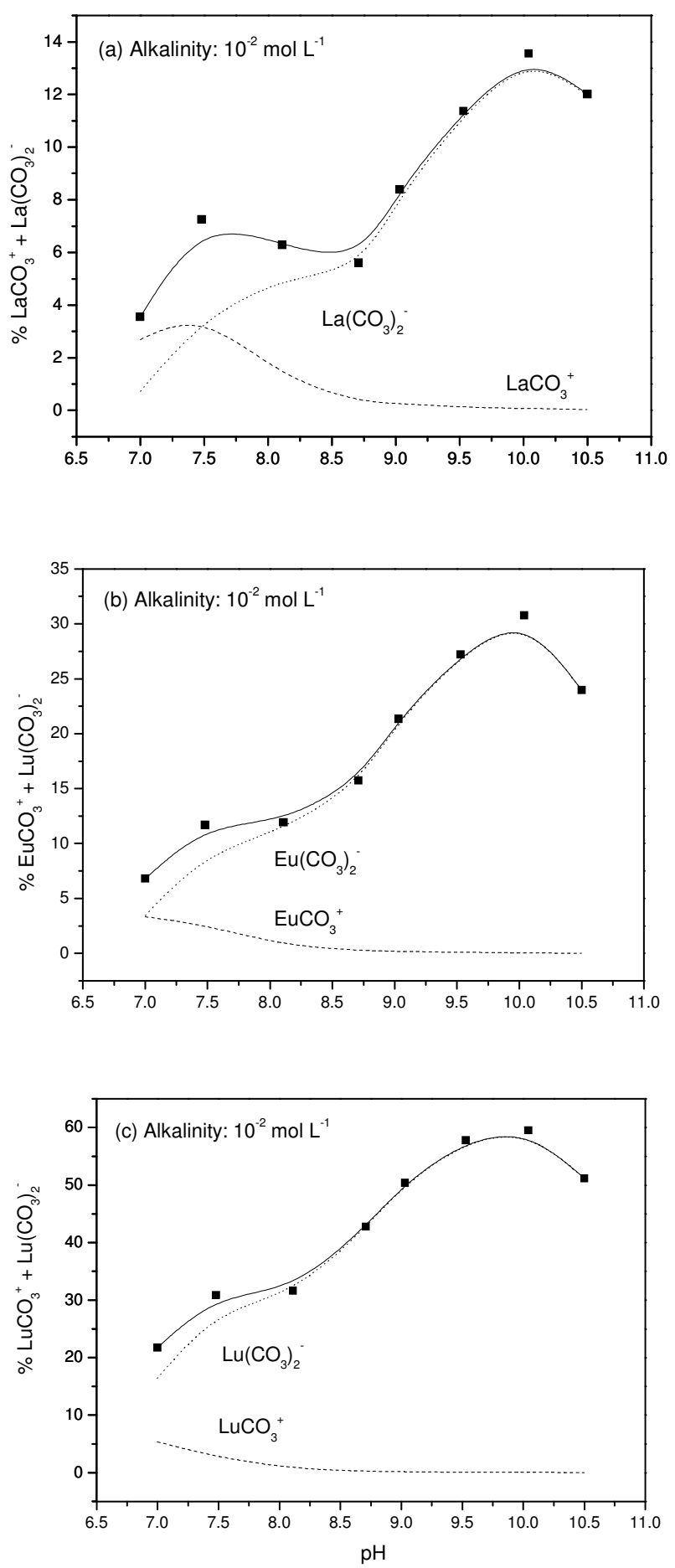

Fig. 1 

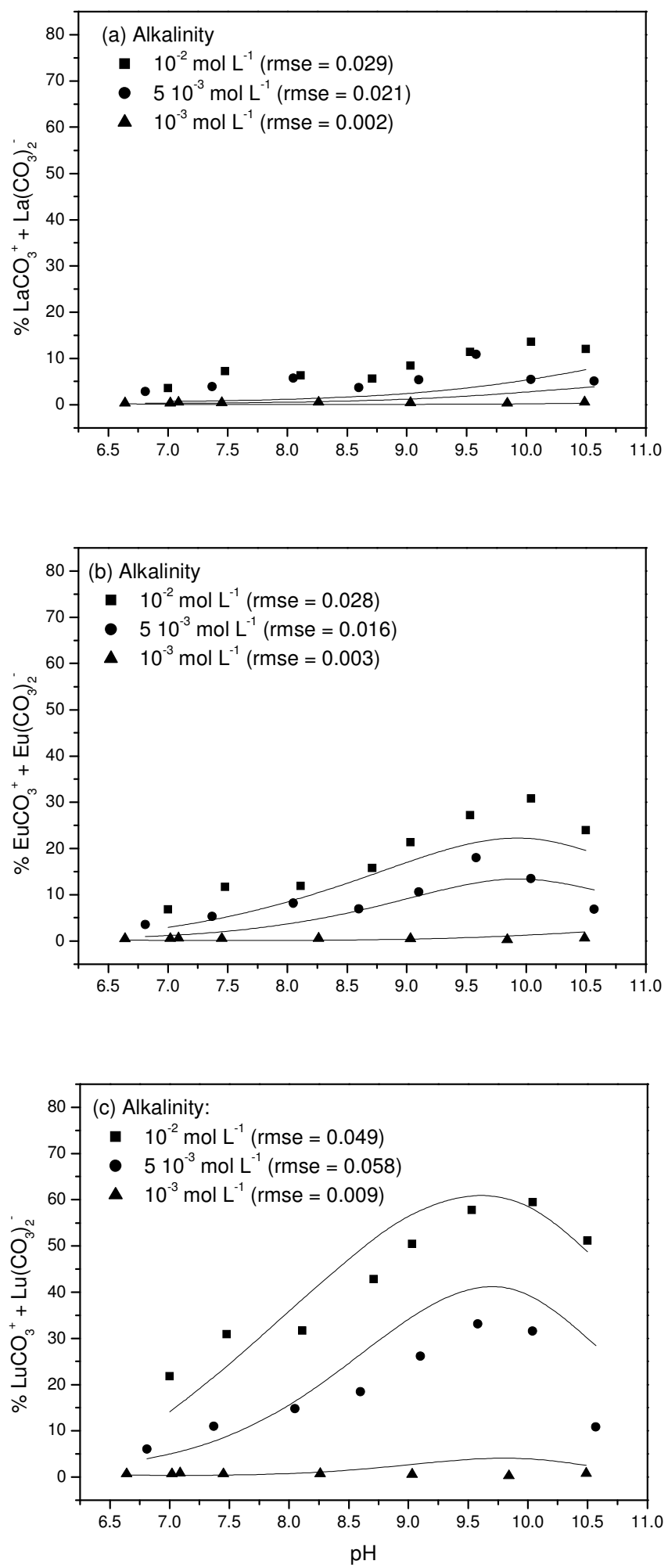

Fig. 2. 